\title{
La violencia en El Salvador
}

...pero nosotros enseñamos sangrientas instrucciones que, al ser enseñadas, vuelven para atormentar al inventor.

William Shakespeare

Pregunta: ¿Cuál es el principal problema que tiene actualmente El Salvador?

Respuesta: Muchos, pero el que está más peor (sic) es el de la delincuencia (Carpintero residente en Tenancingo).

Pregunta: ¿Para usted, ha terminado la guerra en El Salvador?

Respuesta: La guerra política sí, la de la Fuerza Armada y de los guerrilleros; pero la guerra social no (Estudiante universitario).

Pregunta: ¿Cree usted que El Salvador es democrático actualmente?

Respuesta: No porque ahora ni salir a la calle puede uno porque ahí lo asaltan (Señora del mercado).

Pregunta: ¿Comparando la situación actual del país, diría usted que ahora El Salvador está mejor, igual o peor que antes de los Acuerdos de paz?

Respuesta: Mire, yo creo que quizás peor, porque antes si uno no se metía en política no lo mataban, ahora sí, en la casa puede estar y ahí lo matan (Campesina del cantón Cantarrana).

Pregunta: ¿En qué situaciones tiene un hombre derecho a matar a alguien, para defender a su familia o para proteger su propiedad?

Respuesta: Para proteger mi propiedad (Empleado de empresa privada de San Salvador).

Pregunta: ¿Qué le hace sentir orgulloso de este país?

Respuesta: La lucha por sobrevivir (Empleado público).

Pregunta: ¿Qué le hace sentir vergüenza de este país?

Respuesta: La policía (Estudiante de universidad privada).

Las anteriores son respuestas verídicas que han sido dadas a los encuestadores del IUDOP, en distintos sondeos realizados a través de los últimos tres años. Estas opiniones no necesariamente son las más comunes y representativas, pero ilustran muy bien la situación y las preocupaciones del salvadoreño común en torno a un problema que no es nada nuevo. De hecho, las investigaciones de opinión comienzan a señalar a la delincuencia y todas sus implicaciones como problema del país desde 1992 y muestran que se convierte en el principal problema - arriba de los problemas económicos singulares-desde finales de 1993 y principios de 1994. En 1993, el problema de la violencia entendida como delincuencia ya había superado ampliamente la máxima proporción de respuestas que señalaban a la guerra como problema en los ochenta.

En un principio, las preocupaciones por la violencia delincuencial se interpretaron de dos formas. Por un lado, se dijo que era una reacción normal ante un proceso bélico largo y que, por lo tanto, era un fenómeno normal y coyuntural. Por el otro lado, se dijo que era una ilusión generada 
por la prensa, que no tenía otras noticias, pero que la violencia delincuencial siempre había existido. Ambas posturas tenían parte de razón. Es cierto que las guerras suelen generar dinámicas sociales desviantes, así como también es cierto que la violencia delincuencial siempre ha existido en El Salvador. El problema es que ambas posturas trivializaron el problema al otorgarle un carácter de coyunturalidad, por un lado, y de normalidad, por el otro. Tales atribuciones hicieron que nadie la considerase un problema serio e ingenuamente fue olvidada e ignorada.

Ahora, en marzo de 1996, la violencia y la histeria colectiva producida por la misma están dominando la vida social salvadoreña y se toman acciones para hacerle frente. El problema es que la violencia sigue siendo tratada como si fuera algo normal, cuando el Estado legitima su uso; el problema es también que la violencia sigue siendo vista como un evento coyuntural y muchos simplemente esperan que pase, ignorando su responsabilidad en la prevalencia del fenómeno; y, peor aún, la violencia se sigue reduciendo simplemente al problema de la delincuencia. Lo que sigue a continuación es un intento por hacer ver que el problema de la violencia en El Salvador es mucho más complejo de lo que se ha pensado. Para ello se repasan aquellos factores que están interviniendo en la situación y que nos hacen pensar que la violencia, de la forma en que la estamos viviendo en el país, no puede reducirse simplemente a una situación de criminalidad coyuntural.

Hagamos, antes de proseguir, una revisión de lo que nos dicen los registros y las estadísticas formales. Según los datos de la Organización Panamericana de la Salud (OPS), en un breve documento de 1995 sobre los indicadores básicos de salud (ver Situación de salud en las Américas. Indicadores básicos 1995), nuestro país, con tan sólo seis millones de habitantes, ostenta el segundo lugar en la tasa de muertes de personas de sexo masculino por causas externas (homicidios, accidentes y suicidios), en todo el continente americano. Colombia tiene el primer lugar. La misma organización en su informe Las condiciones de salud en las Américas (edición de 1994, vol. 1), revelaba que El Salvador mantenía el segundo lugar en homicidios dentro de la estructura relativa de mortalidad por causas externas. Esto quiere decir que en este país la gente se muere - $-y$, sobre todo, se asesina - con mucha facilidad y con una elevada frecuencia.

Ahora bien, alguien podría dudar de las fuentes de las cuales la Organización Panamericana de la Salud obtiene los datos para construir sus indicadores estadísticos. Veamos, entonces, otra fuente: la Fiscalía General de la República. Sus registros preliminares revelan un total de 7,877 homicidios dolosos en 1995, lo que significa que el año pasado morían asesinadas intencionalmente un promedio de 21 personas diariamente, en todo el país. Si sumamos las 9,135 muertes registradas por la Fiscalía en 1994, tenemos un total de 17,012 homicidios dolosos - no se incluyen los homicidios culposos y otras muertes violentas. Esto quiere decir que en El Salvador, en los dos últimos años, una persona ha sido asesinada cada hora. El cálculo resulta más revelador cuando los datos se consideran desde la perspectiva temporal y geográfica.

Contextualizemos los datos de manera temporal. Por lo general, tácitamente, se atribuye a la guerra civil una duración de doce años. A ciencia cierta no se sabe cuál debiera ser el punto de partida, porque si fuera la ofensiva del 10 de enero de 1981 , evidentemente, serían once y no doce años; si fuera la masacre del 28 de febrero de 1977, en la Plaza Libertad, serían catorce; si fuera el inicio

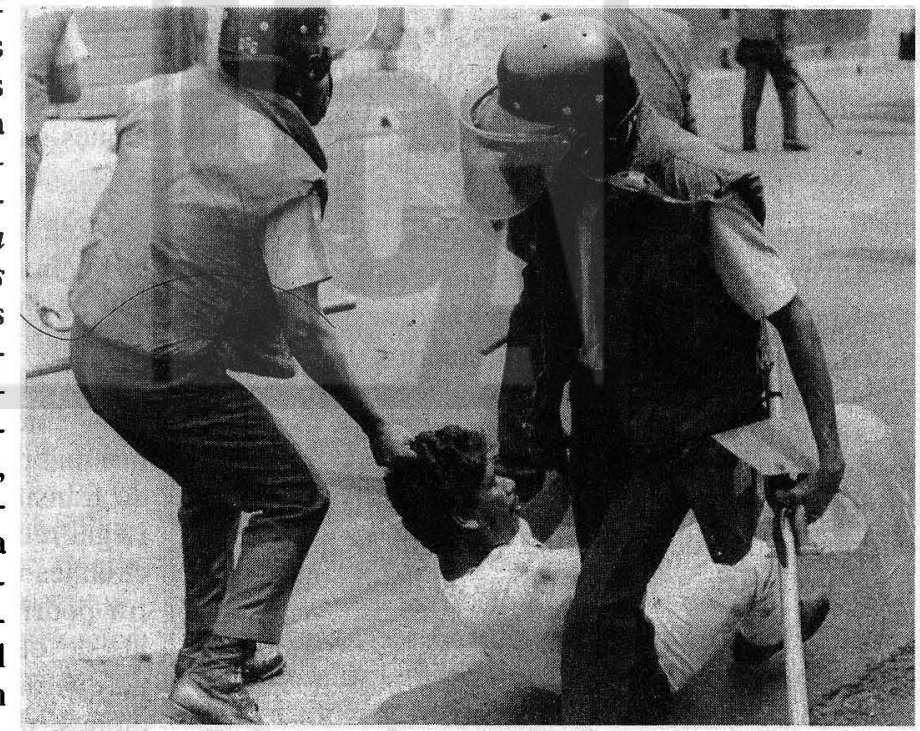


de la lucha guerrillera -en 1970 - serían veintiuno. Pero, manteniendo, sin más, la opinión generalizada de que el conflicto bélico duró doce años, podemos calcular el saldo anual de muertos. Un paréntesis antes de proseguir. Las declaraciones oficiales de Naciones Unidas afirman que fue el doloroso "saldo de muertos y heridos", que enlutaba a la familia salvadoreña, la causa que determinó su participación en el proceso de negociación y pacificación del país. Con un conflicto bélico de doce años de duración y un total de más o menos 75,000 muertes, atribuidas al mismo, tenemos un saldo promedio de 6,250 muertes anuales. De acuerdo a los datos de la Fiscalía, en los dos últimos años se ha registrado un "saldo" anual promedio de 8,506 muertes por la violencia. Esta cifra resulta al promediar los muertos por la violencia de estos años, sin duda mejor registrados que los anteriores. Esto significa, no sólo que ahora somos el segundo país más violento del continente americano, sino que el índice de muertes por la violencia general en la actualidad ha aumentado en un 36 por ciento con respecto al índice registrado por causa de la guerra - lo que hizo necesaria la intervención de Naciones Unidas en las fronteras nacionales. Al cabo de doce años, manteniendo el promedio de los dos últimos años, el luto de la familia salvadoreña, en muertos oficiales por la violencia, sería de 102,072. La mayoría jóvenes de escasos recursos, como en la guerra.

Contextualizemos ahora los datos de forma espacial, geográfica. Sobre los mismos datos de la Fiscalía es posible construir una tasa bruta de homicidios y compararla con otras regiones de América. El resultado es, como muestra el cuadro, muy elocuente. La tabla presenta tasas brutas, no ajustadas. Si hicieramos el cálculo con ajuste de edad y sexo, tomando hombres entre 15 y 30 años de edad, la tasa salvadoreña sería exponencialmente más alta.

Ahora bien, cualquiera podría desestimar estos datos, citando la cantidad de muertes diarias ocurridas en ciudades como Río de Janeiro, donde ciertamente el número es muy alto; pero una cosa es morir asesinado en una ciudad de 15 ó $18 \mathrm{mi}$ llones de habitantes y otra cosa es morir asesinado en una ciudad de un millón y medio de habitantes o en un país de sólo 6 millones de habitantes.

¿Cuáles son las causas de todas esas muertes? ¿Es que acaso todos los homicidios están relacionados con asaltos, robos, secuestros y violaciones?

\section{Tasas de homicidio en algunas ciudades y países de América}

\begin{tabular}{lr} 
Países o ciudades & Tasa/ \\
& 100,000 \\
\hline Ciudades de Nueva Inglaterra, E.U. & 1.7 \\
Canadá & 2.3 \\
Chile & 2.8 \\
Costa Rica & 3.9 \\
Estados Unidos (general) & 8.5 \\
Cartagena, Colombia & 17.6 \\
México & 19.4 \\
Santafé de Bogotá, Colombia & 62.0 \\
Cali, Colombia & 90.9 \\
Todas las ciudades de Colombia & 110.4 \\
El Salvador* & 136.5 \\
Medellín, Colombia & 435.1 \\
\hline
\end{tabular}

Fuente: P.A.H.O. Research Protocol: Attitudes and cultural norms associated with social violence in selected cities of Latin America and the Caribbean.

* La tasa de El Salvador fue añadida a la tabla y se construyó sobre los datos de homicidios dolosos de la Fiscalía General de la República y las proyecciones sobre la población salvadoreña en 1995.

Según los registros llevados por el Instituto de Derechos Humanos de la UCA, sólo el 35 por ciento de las muertes violentas registradas en la prensa nacional el año pasado, estaban asociadas a un hecho delincuencial. El resto de las muertes se dieron en circunstancias muy diversas, tales como el enfrentamiento de maras, el ataque sin más con fusiles o granadas a un grupo de personas, ejecuciones sumarias, etc. Estas situaciones no siempre aparecen asociadas al robo $\mathrm{y}$ al asalto.

Veamos ahora los registros del Instituto de Medicina Legall, de los 1,934 cadáveres reconocidos en la zona metropolitana de San Salvador en 1995 , el 70 por ciento fueron personas asesinadas (en diversas circunstancias) y -en menor medida- suicidios; pero el 30 por ciento de las mismas habría muerto a consecuencia de un accidente de tránsito, cuyo número bruto es alto. Medicina Legal reconoció 600 cadáveres producidos por accidentes de automotores en San Salvador. Esta cifra podría resultar pequeña si se la compara con las de otros países. Sin embargo, al comparar el parque de automóviles del país con el de otras naciones, inclusive de Centroamérica, fácilmente se 
puede ver que en El Salvador mueren exponencialmente más personas por vehículo que en cualquier otro lugar.

Además, los datos de Medicina Legal nos permiten comparar entre sí los datos de homicidios y accidentes de tránsito ocurridos en los meses de
1995. La ilustración revela que los homicidios y los accidentes se comportan de manera muy similar ${ }^{2}$, lo cual nos da razones para apoyar la creencia de que los asesinatos no sólo dependen de lo que se conoce como delincuencia, sino que son parte del fenómeno más global de la violencia.

\section{Muertes violentas en los meses de 1995 según datos de Medicina Legal}

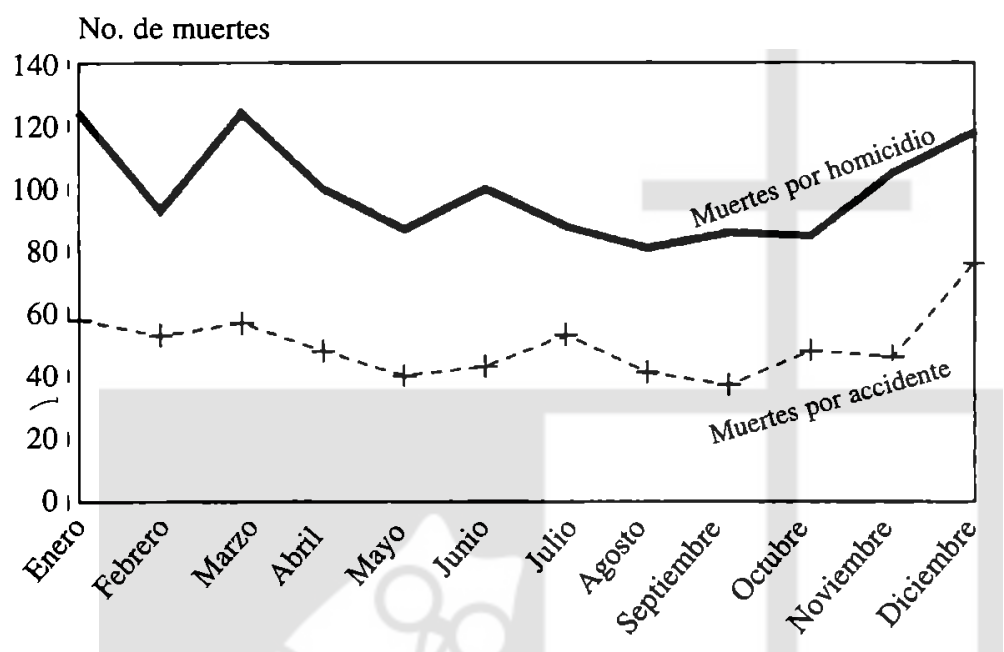

Los datos se refieren a los registros del Instituto de Medicina Legal del área metropolitana de San Salvador

Entonces, viendo todos los datos anteriores, hemos de preguntarnos: ¿realmente han callado las armas en El Salvador? ¿Puede alguien decir que el nuestro es un país pacífico en estos tiempos? ¿Es que acaso los acuerdos de paz nos han convertido realmente en un ejemplo de sociedad en paz y reconciliación? ¿Hemos logrado construir un cultura de paz que merezca ser exportada? En opinión de muchos sí. Es más, a juicio de algunos, el modelo salvadoreño puede y debe ser emulado por otras sociedades en conflicto y, en estas circunstancias hemos llegado a ofrecer a nuestros "experimentados mediadores" a países en conflicto desde hace mucho tiempo, como Colombia, pese a que algunos estudios comienzan a señalar que éste ya no es el país más violento del continente, sino El Salvador (ver Sisti, 1996). En todo caso, por donde quiera que se mire, la violencia ha estado conviviendo en El Salvador, aun después de cuatro años de la firma de la paz. La verdad es que pareciera que cada vez estamos aún más lejos de ser un país pacífico. $\mathrm{Y}$ esto porque paz significa, en primer lugar, la erradicación de la violencia.

La evidencia obtenida en los registros institucionales tanto como la realidad misma señalan que la violencia es más que un problema de delincuencia —entendida simplemente como la vorágine de robos, asaltos, secuestros y extorsiones. Existe un problema más amplio, más complejo y más urgente que se define mejor como violencia.

Todos los indicadores a los que se tiene acceso y que pueden ofrecer una idea acerca de la situación de violencia en El Salvador, señalan que tales condiciones no provienen sólo del crimen de la calle tal como se maneja en el discurso popular y oficial. La violencia producto de las masacres de familias enteras, del enfrentamiento de las maras, de los disturbios de los estadios, de las personas atropelladas por buses y automóviles y, claro, de la delincuencia misma son parte de un fenómeno de agresividad exacerbada que viene deteriorando 
las relaciones sociales salvadoreñas desde antes de la guerra. La delincuencia, que constituye el aspecto más evidente y dramático, es sólo una vertiente de ese gran torrente de violencia en el cual los salvadoreños vivimos en la actualidad.

Así, los salvadoreños no sólo nos debemos preocupar porque podemos morir en un atraco, sino que también nos debemos preocupar por no morir en medio de un enfrentamiento de las llamadas maras, por no terminar debajo de las llantas de un autobús y, desde hace cierto tiempo, por no ser víctima de algún comando de limpieza, como "La sombra negra", o de algún policía que nos confunda con un delincuente por el aspecto. $Y$ todo esto es problema de violencia y no sólo de robos y secuestros.

Es totalmente cierto que la delincuencia común es un problema real y grave, pero no es adecuado entender delincuencia como sinónimo de violencia. Es necesario discernir que el crimen en sus distintas expresiones es, al mismo tiempo, una expresión de ese estado generalizado de agresión en el cual las relaciones sociales salvadoreñas se están ahogando. Así, por ejemplo, no es precisamente un problema de delincuencia el caso de un hombre de Concepción Quezaltepeque que, molesto por el ruido que provocaban unos jóvenes en la calle, salió de su casa disparando y asesinó a más de diez personas. Tampoco es un problema de delincuencia la racha de agresiones intrafamiliares, que registraron las organizaciones que protegen al menor y a la mujer al principio del año. Obviamente, con esto no queremos negar el carácter criminal de las matanzas de familias enteras, del maltrato familiar, de los enfrentamientos de las maras $o$, inclusive, de los accidentes de tránsito producto de la borrachera del conductor. De hecho, la mayor parte de las muertes violentas constituyen un delito $\mathrm{y}$, por lo tanto, son actos delincuenciales, jurídicamente hablando. Pero la mayoría de esos actos no son ejecutados por el clásico delincuente común, sino por cualquier ciudadano. Así, es necesario diferenciar entre lo que pretende ser presentado como el origen de todos los males, de lo que realmente está ocurriendo en la situación actual.

Esto nos lleva a plantear que el problema de la violencia en El Salvador está vinculado también con la elaboración ideológica que se ha hecho alrededor del mismo. Definir el problema como delincuencia contribuye a ocultar y a distraer la aten- ción de aquellos factores que hablan de su complejidad. Así, al igual que lo que sucedió con la guerra, el supuesto más o menos implícito -manejado tanto en el discurso de los funcionarios como en la opinión de sectores amplios de la población- es que la violencia constituye una realidad externa a las personas, una situación que está afuera y que desde ahí nos afecta a todos. De esta manera, la violencia se convierte en un objeto externo denominado delincuencia. Al hacerlo, se facilitan los mecanismos sociales que convierten a los delincuentes en los únicos responsables de todos los males de la violencia y con ello se justifican las de estrategias y políticas para contrarrestarlos, recurriendo los mismos mecanismos que los criminales usan.

Así, lo que pocas veces sale a la luz es que al definir al problema como delincuencia y al ubicarlo en el exterior, se ignoran las responsabilidades propias en la prevalencia del fenómeno y se niegan las dinámicas que toleran y estimulan la violencia, incluyendo la delincuencia misma. Si el problema se encuentra afuera, la solución escogida usualmente se reduce a su eliminación física, tal como se hace con una plaga de insectos al rociarle insecticida. El pensamiento clásico en estos casos sostiene que si el problema son los delincuentes, entonces hay que acabar con ellos: "hay que construir una cárcel grande para todos ellos" y el problema estará resuelto. Pocas veces se piensa que el problema de la violencia, como el de la delincuencia, es parte de un mismo fenómeno estructural, proveniente de las mismas condiciones sociales que gestaron la guerra y que en la actualidad permiten, por ejemplo, la proliferación de las maras tal como en el pasado permitieron la existencia de los escuadrones de la muerte.

El punto es que la elaboración ideológica de la violencia como delincuencia no sólo reduce el problema, sino que también atribuye estereotipos: define quiénes son los buenos y quiénes los malos, y define las atribuciones de esos "malos". Así, los desempleados, los jóvenes, los marginados, los que se ven distintos, los homosexuales e inclusive los enfermos, entre otros, se convierten en personas peligrosas que deben ser eliminadas.

Ciertamente, hay que aceptar que buena parte de las muertes violentas en nuestro país desde el fin de la guerra se debe al problema del crimen, pero hay que considerar que detrás de cada asesinato no existe simplemente el perverso deseo de 


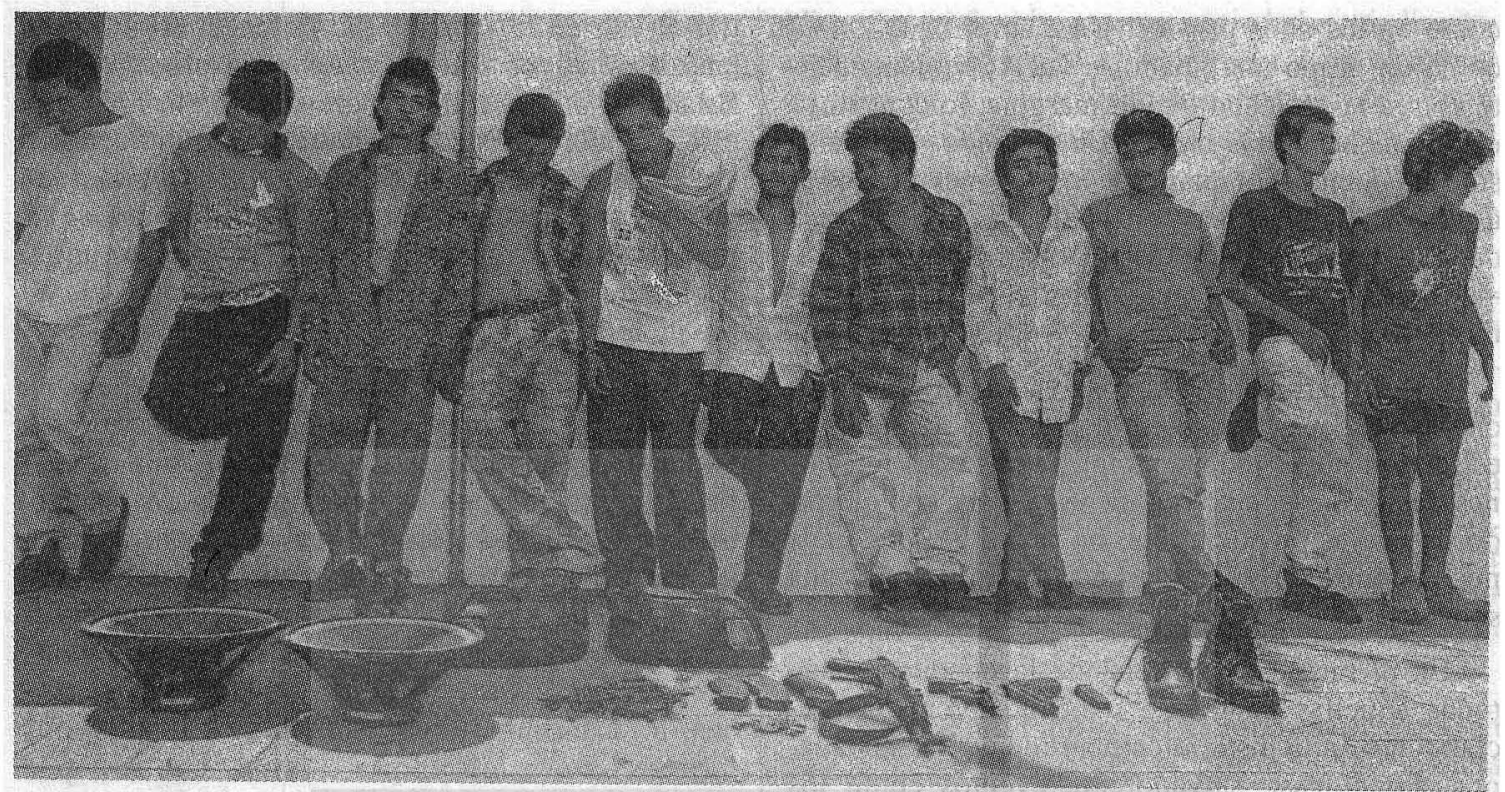

un criminal por hacer daño, sino que en la prevalencia de asesinatos en El Salvador, en la anarquía de agresividad que sufre nuestra sociedad, intervienen una infinidad de aspectos que van desde la intensa marginación social, en la cual han vivido las mayorías de este país, pasando por la cultura de agresión aprendida por pautas sociales y estimulada por' años de enfrentamiento bélico, hasta aspectos que tienen que ver con la impunidad y la disponibilidad de armas.

Hay una cosa que no se puede negar y que es necesario asumir completamente: el fenómeno de la violencia es muy complejo y nunca aparece o se mantiene como resultado de una sola variable o condición. Sin embargo, la investigación sobre la violencia ha permitido agrupar las variables en cuatro grandes áreas de incidencia. Detrás de cada acto de violencia existe (a) una estructura social muy excluyente, (b) un marco psicosocial de conducta, (c) un entorno de permisividad hacia la disposición y portación de armas y (d) unos sistemas de justicia y seguridad pública deficientes.

Todas las sociedades en la actualidad enfrentan el problema de la violencia, el punto está en que algunas sufren tal dificultad de una manera más intensa que otras. Una de las condiciones que suele estar muy presente en aquellos países considerados como más violentos es el alto nivel de marginación que padece buena parte de su población. Los estudios sobre la violencia han señalado, sin embargo, que esa marginación no se limita a la exclusión socioeconómica, o más bien, no es equivalente cien por ciento a pobreza (ver Guerra de Macedo, 1994). La violencia usualmente toma lugar en contextos donde por razones étnicas, políticas, religiosas, económicas y sociales se excluye a buena parte de su población; en entornos que limitan el ejercicio del poder social a amplios sectores de su ciudadanía y en ambientes que reflejan unas desigualdades sociales profundas. La violencia aparece así como la reacción de tales sectores en un esfuerzo por reclamar y recuperar su espacio en la sociedad y como un llamado de atención hacia los que detentan el poder, los privilegiados de tal realidad. En el fondo, la violencia surge como una respuesta social de quienes se encuentran frustrados por la marginación (ver Instituto de Investigaciones de las Naciones Unidas para el Desarrollo Social, 1995).

La marginación socioeconómica, la exclusión en el ejercicio del poder social y là descalificación de los desposeídos han sido y siguen siendo uno de los grandes problemas que tiene nuestro pequeño país. A pesar del fin de la guerra y, sobre todo, del intento por construir una sociedad democrática, representado en los acuerdos de paz (al menos en el espíritu), no se puede negar que El Salvador está aún muy lejos de ser una sociedad justa e igualitaria. Las diferencias sociales parecen estar acentuándose más y la falta de participación en el ejercicio del poder sigue siendo tan considerable 
como en los años previos. Un ejemplo que ilustra cómo un grupo marginado se vuelve violentamente contra la sociedad que lo margina, lo constituye el fenómeno de las maras. En el fondo, las maras son un intento por parte de los jóvenes desposeídos salvadoreños para resocializarse en entornos donde recuperan el poder y obtienen el aprecio -muy a su manera - que la sociedad les ha negado.

Así, la estructura social salvadoreña tiene mucho de responsabilidad en la situación actual. Esta estructura no se reduce simplemente a las relaciones económicas, sino que tiene que ver con el grado de exclusión social que ha permitido que unos pocos controlen y decidan el destino de toda una sociedad.

En el marco psicosocial de la conducta están todas aquellas pautas de relación aprendidas socialmente en la historia compartida de los ciudadanos. En el caso salvadoreño, eventos como los acuerdos de paz difícilmente pueden borrar o, de suyo, cambiar las pautas de relación aprendidas históricamente. No será nada atrevido entonces afirmar que, a pesar del fin de la guerra y de los supuestos esfuerzos por crear una "cultura de paz", la violencia postbélica no es nada nuevo; por el contrario, se ha institucionalizado en el país. En otras palabras, la violencia es ya una institución social.

Esto quiere decir que lo que antes constituía una manera concreta para actuar en ciertas circunstancias y en ciertos grupos específicos para resolver problemas y diferencias o para satisfacer necesidades, se ha venido convirtiendo en una pauta habitual de comportamiento de toda la sociedad hasta el punto de volverse normativa. Con la institucionalización se crea la cultura de la violencia, la cual se encarga de reproducir y extender las normas y los valores aprendidos en los sucesos especiales de la historia de una nación. Mediante la institucionalización, esạs pautas llegan a cristalizarse y se convierten en "lo normal". Lo anómalo se convierte en la regla. Entonces, los roles de los ciudadanos, recíprocos y complementarios, incluso aquellos regulados por normas tácitas, se imponen sobre el orden legalmente constituido. Pero la cultura de la violencia no sólo se refiere a la forma institucionalizada más o menos agresiva como reaccionan unas personas frente a otras. La cultura de la violencia se origina en la forma en que el Estado mismo ejerce sus funciones y legiti- ma el uso de la fuerza y la violencia para lograr ciertos objetivos con el pretexto de promover un Estado de derecho, donde prevalezca el orden. En este sentido, el Estado promueve la cultura de la violencia en la medida en que responde a las demandas sociales, sean éstas justas o injustas, de la misma manera agresiva. Es más, la reciente aprobación de la ley de emergencia es un claro ejemplo de lo anterior ${ }^{3}$.

En una situación de violencia informal - aunque cada vez es más formal- como la que está viviendo El Salvador, cuyas causas además son difusas, los roles están claramente definidos socialmente: por un lado, los delincuentes; por el otro, la gente honrada; y, también cabría mencionar, a las autoridades. No obstante, con la institucionalización, todos esos actores hacen uso de la violencia para relacionarse socialmente y todos la justifican, a su manera. Lo que cambia es la finalidad expresa.

Sin embargo, la elaboración ideológica que se ha hecho de la violencia al centrarla exclusivamente en el crimen, sobre todo en la delincuencia común, ignorando el crimen organizado o la corrupción en las instituciones del Estado, ha supuesto la definición de valores que exaltan la fuerza y la represión ante cualquier asomo de desorden; que estimulan la paranoia y la intolerancia, las cuales suponen también el estímulo de comportamientos violentos ante cualquier asomo de sospecha. Pero sobre todo, la elaboración ideológica de la violencia está permitiendo que el Estado legitime nuevamente, sin duda con el apoyo de los ciudadanos, el uso de su fuerza para controlar a una parte de los mismos, lo cual pone en serio peligro a la institucionalidad democrática del país; además de que induce a ignorar la responsabilidad de los ciudadanos en la prevalencia del problema.

Así, repetimos, no todas las muertes y agresiones que sufren los ciudadanos salvadoreños tienen su raíz en el intento de asalto cometido por un joven psicópata, traumado por la guerra. Está suficientemente probado que la mayor parte de la violencia, aun en las sociedades más patológicas, tiene fines instrumentales; es decir, no se mata por el placer de matar o por una crisis esquizoide. Por lo general, se asesina porque se quiere lograr algo o para alcanzar un objetivo; lo que está ocurriendo en El Salvador es que la institucionalización está convirtiendo esto en una práctica universal para resolver cualquier conflicto, es decir, lo que co- 
menzó como práctica esporádica con fines instrumentales, en situaciones límites, se ha extendido de tal forma que, ahora, matar por robar un par de zapatos o porque el otro no es tolerado por ser homosexual o miembro de una determinada familia, es ya una práctica común cuando no obligada.

Tras lá violencia imperante en una sociedad existe siempre una amplia y poco reglamentada disponibilidad de armas e instrumentos de agresión. En el caso salvadoreño, llama la atención cómo en el último año han proliferado los negocios legales de venta de armamento, es más, no es difícil imaginar cómo pueden haber crecido las ventas ilegales de armamento. Sin duda, el conflicto bélico dejó una cantidad considerable de armamento circulando por las calles, arsenal que pese a los señalamientos, las autoridades competentes no han sido capaces de controlar. Sin embargo, a estas alturas, el problema ya no es sólo que hubo una guerra y quedaron armas regadas hay que recordar que no es la guerra la causante de todos nuestros males-, el problema es que, prácticamente, cualquier persona puede obtener una pistola o una escopeta (no "armas de guerra") por un precio relativamente módico y sin dificultades para obtener un permiso de portación.

Argumentando que no se puede dejar desprotegida a la ciudadanía frente a la delincuencia, se permite y estimula la adquisición y la portación de armas, y se entra a una espiral donde los delincuentes y los ciudadanos deben armarse más y ser más perversos que el rival para poder sobrevivir; cuando lo que ocurre en consecuencia es todo lo contrario, se asegura más la propia muerte. En síntesis, no se trata sólo de la disponibilidad de armas, sino también de la laxitud de las leyes que rigen su portación. Gran parte de los homicidios podrían haber sido evitados si los asesinos no hubiesen tenido acceso fácil a un arma. Hay que tener en cuenta que muchas de las armas usadas por los homicidas han entrado en circulación de forma legal.

Finalmente, y probablemente uno de los aspectos más determinantes de la situación de violencia, es la situación de los sistemas de justicia y seguridad pú- blica. La violencia en una sociedad está directamente relacionada con la manera más o menos efectiva en que funcionan los sistemas de seguridad y justicia. En este sentido, es clave que ambos sistemas permitan la impunidad. No es secreto que El Salvador tiene que caminar mucho aún antes de poder llegar a que los sistemas de seguridad pública y justicia funcionen eficientemente. En la medida en que el aparato de justicia sea vulnerable a la corrupción, tanto como en la medida en que la Policía Nacional Civil viole las normas al debido proceso, porque "hay que ser duros con los delincuentes", en esa medida, la impunidad seguirá campante, estimulando la situación de violencia. En este sentido, el punto central no es imponer leyes más drásticas para combatir a los delincuentes, sino lograr que el sistema funcione adecuadamente.

La impunidad no surge porque las leyes sean deficientes o blandas, sino que está relacionada con la incapacidad, voluntaria o no, del sistema para aplicar tales leyes. En el fondo, nuestra sociedad enfrenta un problema de aplicación de sus leyes más que de eficiencia de las mismas. En un país en el que ni siquiera sę respetan las leyes más elementales, esto es, los derechos consignados en la Constitución, los cuales protegen y garantizan la dignidad de la vida humana, cómo se espera que las leyes penales sean observadas y garanticen lo que el texto fundamental no logra.

El problema radica en que la práctica legal ha creado otras normas, paralelas a las leyes consig-

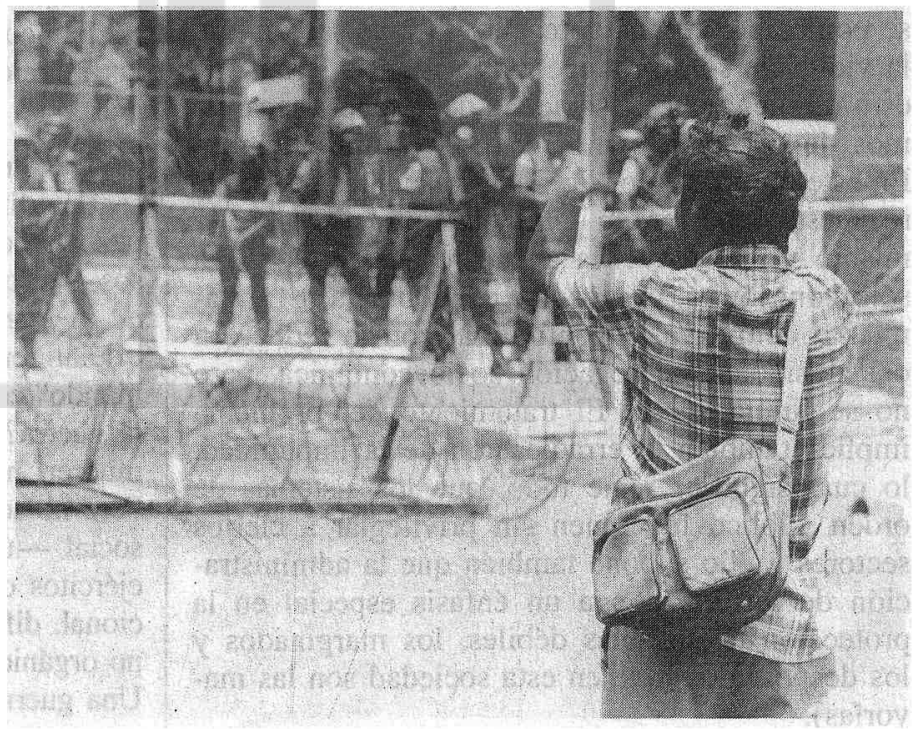


nadas formalmente. Así, los procedimientos jurídicos se rigen más por esas normas creadas por años de corrupción y de interpretación selectiva de los códigos penales que por la aplicación pareja del texto legal y eso es, justamente, lo que ha fomentado la impunidad.

No es nada nuevo afirmar que en El Salvador la erradicación de la impunidad se encuentra todavía muy lejos, sobre todo, en la medida en que no se comprendan cosas como que la verdad sobre lo que ha sucedido en el pasado y sobre lo que sucede ahora debe salir a flote de una vez por todas. La impunidad que padece la sociedad salvadoreña no es consecuencia de la erradicación de los antiguos cuerpos de seguridad, ni mucho menos es resultado del esfuerzo por hacer prevalecer los derechos humanos de la población - como algunos funcionarios han sugerido. La impunidad que debilita los sistemas de seguridad pública y justicia es resultado de leyes y procedimientos que históricamente han sido aplicados de manera selectiva, de amnistías fáciles e irresponsables cuando los inculpados están vinculados al poder y de procedimientos policiales que violan las normas del debido proceso.

En una situación de impunidad generalizada, donde no se respetan las leyes, se llega a situaciones como la actual, en la cual los medios de transporte - buses, microbuses y automóviles- se convierten con espantosa regularidad en instrumentos de muerte.

Dicho lo anterior, es claro que la violencia no se combate con más agresión, pues es sabido que la violencia sólo produce más violencia - aunque esto no niega que la sociedad deba tener mecanismos de coacción como recursos de última línea. En este punto, hemos de estar concientes de que la respuesta debe ser tan compleja como el problema mismo y que reducirla a una respuesta represiva sólo contribuirá a empeorar el problema. El tratamiento comienza, en definitiva, con la reducción del abismo de segregación socioeconómica, pero no se limita a eso. El tratamiento del problema implica también la erradicación de la impunidad, lo cual significa, ante todo, que los sistemas de orden público funcionen sin privilegiar a ciertos sectores y ello supone también que la administración de justicia ponga un énfasis especial en la protección de los más débiles, los marginados y los desposeídos (que en esta sociedad son las mayorías).
Es necesario entender que el tratamiento de la delincuencia pasa por la revisión de las actitudes propias, que estimulan la impunidad y la ineficiencia del sistema judicial. Es preciso lograr que el tratamiento de la violencia delincuencial pase primero por un examen serio de la eficiencia de las leyes ya existentes y su aplicación antes que promulgar otras nuevas. Es obligatorio que el tratamiento de la delincuencia aborde el problema de la disponibilidad y del tráfico de armas, algo que fue ignorado al final de la guerra, permitiendo sacar ganancia de lo que quedó del conflicto. El tratamiento de la delincuencia debe incluir políticas para controlar aquello que la televisión pone como modelo de comportamiento. El tratamiento de la delincuencia debe rescatar las recomendaciones del Grupo conjunto, que vinculan a los escuadrones de la muerte con el crimen organizado. Es necesario revisar las responsabilidades sociales hacia la juventud salvadoreña y diseñar políticas de desarrollo social para los jóvenes de escasos recursos. De hecho, muy pocas veces se le han dado a los jóvenes de Apopa, Soyapango, etcétera, otras alternativas que la pertenencia a las maras.

Es imperativo no sucumbir ante la histeria de la delincuencia, para no olvidar que la violencia tiene parte de su raíz en las frustraciones de buena parte de la población, derivadas de su lucha por la supervivencia, en situaciones de marginalidad, pobreza e injusticia estructural, y que, a pesar de los cambios políticos, las condiciones siguen siendo iguales. No se debe pasar por alto que mientras no se ataquen de una vez por todas esas condiciones, la delincuencia y la violencia seguirán socavando las relaciones sociales y debilitando el tejido social.

De otra forma, lo que seguiremos teniendo no será un difícil proceso de postguerra, como tampoco paz o reconciliación, sino - en el mejor de los casos- lo que habremos de llamar la informalización de la guerra. Y entonces, ¿tiene sentido clausurar oficialmente el "proceso de paz modelo para el mundo" con semejante saldo? ¿Es que ha terminado la guerra? Está claro que los que matan y los que mueren no tienen estatuto de fuerza beligerante. Pero no se podrá negar que son parte de una guerra social - una "guerra social". No la guerra de los ejércitos o de las guerrillas, pero sí una guerra nacional, difusa y no oficial. Una guerra de combates no orgánicos, sin ideas y sin proyectos de sociedad. Una guerra que nos está empujando a un grotesco 
enfrentamiento de los bien vestidos contra los mal vestidos.

\section{Instituto Universitario de Opinión Pública}

(IUDOP)

\section{Referencias bibliográficas}

Guerra de Macedo, Carlyle. (1994). "Sociedad, violencia y salud: una nueva agenda para la democracia". En Conferencia interamericana sobre sociedad, violencia y salud. Washington: Organización Panamericana de la Salud.

Instituto de Naciones Unidas para el Desarrollo Social. (1995). Estados de desorden. Los efectos sociales de la globalización. Londres: UNRISD.

Sisti, Elvio. (1996). La violencia juvenil en El Salvador: una perspectiva psicosocial. San Salvador: (Mimeo).

\section{Notas}

1 Un problema que aparece cuando se estudia la violencia es que no existe un mecanismo estandarizado y centralizado de registro de muertes. Cada institución lleva el conteo a su manera, muchas veces de forma nada sistemática. De ahí la diferencias en los registros. Sin embargo, ello no niega la validez del dato.

2 Nuestra afición por la estadística nos impulsó a someter estos datos a una prueba de correlación. El resultado fue de 0.70 con un $\mathrm{p}<0.05$, lo cual significa que las prevalencias de los homicidios y de las muertes por accidentes tienen un comportamiento similar a través del tiempo.

3 Una acotación añadida en la revisión del presente comentario: la prensa nacional registró un promedio de 15 muertes violentas semanalmente, en los primeros tres meses y medio del año, esto es, hasta la aprobación de la ley de emergencia el 19 de marzo; luego de la aprobación de ésta, la semana cerró con 23 muertes violentas, 8 de ellas atribuidas a agentes de la policía . 